\title{
Sleep quality assessment among college students using Pittsburgh Sleep Quality Index in a municipal corporation area of Uttarakhand, India
}

\author{
Ranjeeta Kumari ${ }^{1}$, Kapil Jain ${ }^{2}$, Bhola Nath ${ }^{3}$ \\ (Index words: sleep quality, PSQI, PSS-10, stress, yoga, mobile use)
}

\begin{abstract}
Introduction Poor sleep quality have been reported among adults in most countries and are increasingly been reported in their predecessors, the college students. The present study aimed to assess sleep patterns and determine its association with various correlates amongst college students for effective and timely interventions in the habit-forming years of the life.
\end{abstract}

Methodology This was a cross sectional study done among college students enrolled in different courses, in Rishikesh municipal corporation area, in Dehradun district of Uttarakhand, India. Sleep Quality was assessed using a validated Pittsburgh Sleep Quality Index (PSQI), which has seven components while Perceived Stress Scale-10 assessed stress.

Results Poor sleep quality was reported among $66 \%$ of respondents. Mean sleep latency among respondents was 27.2 minutes (SD $20.75 \mathrm{~min}$ ), with a median and mode of 20 minutes and 60 minutes respectively. On logistic regression analysis, yoga/ meditation, which have been recognized as effective relaxation techniques since ages, were found to have a positive association with better sleep quality (OR $0.47,95 \% \mathrm{Cl}(0.26-0.84)$. Stress (OR 4.10, 95\% Cl 1.71-9.83) and mobile use before bedtime (OR 1.956, 95\% Cl: 1.02-3.75) were also significant predictors of poor sleep quality.

Conclusions and recommendations The prevalence of poor sleep quality was quite high. Relaxation techniques such as yoga/ meditation and stress relieving workshops may pay rich dividends. Use of electronic devices before bedtime need to be restricted for better sleep quality.

Ceylon Medical Journal 2020; 65: 86-94

DOI: http://doi.org/10.4038/cmj.v65i4.9279

\section{Introduction}

Sleep is a periodic resting state of natural arousable unconsciousness of body and mind, which leads to the retuning of body and mind [1]. A good quality sleep has been shown to be an essential component of health, and its deprivation being linked to various diseases [2].

Sleep deprivation is defined as getting inadequate sleep, i.e. less than 7-9 hours per day $[3,4]$. Other components of poor sleep quality (PSQ) include sleep latency, restless sleep and insomnia [5]. Experiments in sleep deprivation among volunteers have shown that a sleep-deprived person is incapable of sustaining normal levels of efficiency, both physically and mentally [6].

The worldwide statistics on sleep reports of 48 countries shows that not even one country manages an average of 8 hours of sleep/night. The five worst countries in order of worst sleepers include Japan, Saudi Arabia, Sweden, India and Philippines [7]. Although, sleep deprivation is generally a disorder of elderly and sick individuals, PSQ have increasingly been reported among college students and is considered a global public health problem [8]. This compromises students' goals, by affecting learning, memory, grades, absenteeism etc. [9]. The causes of PSQ are many - physiological and psychological, internal and external and their solutions depend on the identified cause [10]. Studies have reported that, sleep problems are generally ignored by both the individuals as well as doctors due to apathy [11].

Youth of a country are its asset for future social and economic development and investing on their health is a matter of prime importance. The prevalence and impact of PSQ is expected to be more deleterious in this group due to self-declared independence. This necessitates assessment and evaluation of sleep patterns and its relation to various correlates among college students for timely intervention, representing the investment of a nation.

Rishikesh, known as "Yoga capital of the world", is a municipal corporation in the state of Uttarakhand. It is expected that sleep pattern of college students here is different from other parts of the country due to its deeprooted connections with spirituality. The present study

${ }^{1}$ Department of Community and Family Medicine, AIIMS Rishikesh, Uttarakhand, India, ${ }^{2}$ Department of Pediatrics, PGIMER Chandigarh, ${ }^{3}$ Department of Community and Family Medicine, AlIMS Bathinda, Punjab, India.

Correspondence: BN, e-mail: <bholanath2001@gmail.com>. Received 29 April 2020 and revised version 04 November 2020 accepted 02 December 2020.

This is an open-access article distributed under the terms of the Creative Commons Attribution License, which permits unrestricted use, distribution, and reproduction in any medium, provided the original author and source are credited. 
was undertaken with objectives of estimating the prevalence of sleep deprivation among college going students of Rishikesh and to determine its association with various correlates for suggesting appropriate interventions for timely correction.

\section{Methods}

\section{Recruitment of participants}

The present study was a cross-sectional study conducted among college students of selected degree colleges of Rishikesh. Reason for choosing college students was because of their different physiological, social, psychological and contextual factors, posing greater risk for chronic insufficient sleep [12,13].

Multistage random sampling was used to select the sample population. Rishikesh, a sub-district of Uttarakhand has 7 colleges. Three colleges consented to participate in the study. Five courses were randomly selected from these colleges and approximately 69 students were enrolled from each course randomly. Some courses had a reduced strength of students and therefore students from other courses were selected to make up for the sample size. For those courses having more than 70 students, a simple random sampling without replacement was done, whereas for other courses, all the students present on the day of data collection were enrolled.

All individuals attending college on the day of interview were eligible for inclusion in the study. The respondents enrolled voluntarily after an explanation of the study objectives and methods in classroom. Respondents filled up the questionnaire, which was in English, in the presence of one of the authors, who cleared any doubts regarding the questionnaire. The duration of the study was six months, which included three months of data collection from July to September 2018.

Exclusion criteria: Those individuals not willing to participate, and those suffering with any acute or chronic illness requiring medications, which might affect sleep (mood stabilizers, hypnotics, stimulants, antihistamines, etc.), were to be excluded from the study. However, none of the respondents met these exclusion criteria.

Sample size: Prevalence of sleep deprivation as reported in an Indian study was $34.2 \%$ [14]. Sample size was calculated using the formula $\mathrm{Z}_{(1-\alpha) / 2}^{2} \mathrm{pq} / \mathrm{L}^{2}$ [15], where, Desired confidence level $=95 \%, Z_{(0.05)}=1.96$, $\mathrm{p}$ (prevalence rate) $=34.2, q=1-\mathrm{p}=65.8, \mathrm{~L}=$ least permissible error (absolute precision $)=5 \%$. The sample size obtained was $=345.6 \approx 346$.

Variables: The outcome variable in the study was sleep quality, which was assessed using Pittsburgh Sleep Quality Index (PSQI) questionnaire, which is a validated questionnaire for assessment of sleep patterns and its predictors in college going students, developed by University of Pittsburgh and has been used in researches conducted in Indian population. It is a self-reported questionnaire that assesses sleep quality over a 1-month time interval, and addresses 7 components i.e. subjective sleep quality, latency, duration, efficiency, disturbance, need for medications to sleep and day dysfunction due to sleepiness, with maximum score being 21 points. A cut-off of five was considered to identify respondents with poor sleep quality [16].

A predesigned pretested questionnaire was used to assess sociodemographic, behavioural, health and study related variables. Responses to self-satisfaction and parents' satisfaction with studies were recorded as dichotomous subjective responses “yes” or "no”. Current use of tobacco was defined as use of any amount and form of tobacco, daily in the past 7 days. Ever use of alcohol was reported as having alcohol anytime in life as a drink. Alcohol use was assessed using AUDIT-C questionnaire. In men, a score of 4 or more was considered optimal for identifying hazardous drinking or active alcohol use disorders while in women, a score of 3 or more was considered positive [17]. Perceived stress scale 10 (PSS 10 ), which is a validated scale, measured perceived stress [18]. Information about the type of activity during recreation was assessed using questions from Global Physical activity questionnaire from WHO, which is a validated tool [19]. The responses for activity during work was similar for all students and therefore not included in the analysis.

Data analysis: Data was entered in Microsoft Excel ${ }^{\circledR} 2010$ and analysed using statistical software SPSS 23.0. For proportions, Pearson's Chi-square or Fisher's Exact Test (when necessary) were applied to find out significant association between independent and dependent variables. Bonferroni Chi-square residual analysis was done for post hoc analysis after chi square test for $\mathrm{n} \times \mathrm{n}$ table, where $n>2$. Independent $t$ test was used to compare means in two groups. Binary Logistic regression was used to determine the predictors of PSQ after controlling for confounding variables. A p value of less than 0.05 was considered significant.

Ethical considerations: Ethics permission was obtained from the Institutional Ethics Committee. Students who agreed to participate in the study signed an informed consent form after explaining that they were entitled to leave the study at any time and anonymity was promised.

\section{Results}

Mean age of respondents was 20.14 years (SD 1.76). The proportion of girls (64.5\%) was more than boys. Enrolment rate from different courses ranged from $15.5 \%$ to $23 \%$. Most of the students (68\%) were in their 1st and 2nd year of study. $62.4 \%$ respondents were hostellers. About $30 \%$ of respondents were not satisfied with their studies, whereas about $17 \%$ felt that their parents were not satisfied. $20.3 \%$ of respondents practiced yoga or meditation with a mean duration of 39.5 minutes (SD 35.89) 
per session. Proportion of students undertaking vigorous or moderate activity at recreation were $53.7 \%$, while $73.7 \%$ also did sedentary activity for recreation. Mobile use just before bedtime was reported by $85 \%$ respondents (Not shown in Table).

Based on responses to PSQI questionnaire, the pattern of sleep assessment showed that about $12 \%$ of students rated their subjective sleep quality to be "fairly bad" or "very bad". About one fourth of the students had a sleep latency of $>30$ minutes. Mean sleep latency was 27.2 minutes (SD 20.75), with a median and mode of 20 and 60 minutes respectively. More than half of the respondents had a sleep duration of $<6$ hours/day, with a range of 3-10 hours and a mean, median, mode of 6.26, 6 and 6 hours per day respectively. Habitual sleep efficiency of $<75 \%$ was observed in about $14 \%$ respondents. About
$85 \%$ of the respondents reported sleep disturbances, on account of waking at night, getting up to use bathroom, difficulty in breathing, snoring, feeling too hot or cold, bad dreams, pain or other reasons. About 6.8\% reported using sleep medications. $61.5 \%$ respondents reported daytime dysfunction and reduced enthusiasm over the last month, due to sleep disturbances and inadequate sleep. Global PSQI scores calculation concluded that $66 \%$ of respondents had PSQ. Mean PSQI score was $5.78 \pm 2.55$, with a median and mode of six and seven respectively and a maximum score of 15 (Table 1 and Figure 1).

Sociodemographic characteristics including housing conditions such as number of family members, number of rooms in the house, overcrowding etc, were not associated with PSQ. Course or the year of study also did not have a significant association with PSQ (Table 2).

Table 1. Distribution of sleep quality based on Pittsburgh Sleep Quality Index (PSQI) questionnaire

\begin{tabular}{|c|c|c|c|c|c|c|c|c|}
\hline \multirow[t]{3}{*}{ Components of PSQI } & \multicolumn{8}{|c|}{ Scores of components of PSQI } \\
\hline & \multicolumn{2}{|c|}{0} & \multicolumn{2}{|c|}{1} & \multicolumn{2}{|c|}{2} & \multicolumn{2}{|c|}{3} \\
\hline & No. & $\%$ & No. & $\%$ & No. & $\%$ & No. & $\%$ \\
\hline 1. Subjective sleep quality & 119 & 35.5 & 176 & 52.5 & 28 & 8.4 & 12 & 3.6 \\
\hline 2. Sleep latency & 76 & 22.7 & 167 & 49.8 & 76 & 22.7 & 16 & 4.8 \\
\hline 3. Sleep duration & 54 & 16.1 & 99 & 29.5 & 160 & 47.8 & 22 & 6.6 \\
\hline 4. Habitual sleep efficiency & 230 & 68.7 & 57 & 17.0 & 35 & 10.4 & 13 & 3.9 \\
\hline 5. Sleep disturbances & 48 & 14.3 & 242 & 72.2 & 43 & 12.8 & 2 & 0.6 \\
\hline 6. Use of sleeping medications & 312 & 93.1 & 12 & 3.6 & 3 & 0.9 & 8 & 2.4 \\
\hline 7. Daytime dysfunction over the last month & 129 & 38.5 & 147 & 43.9 & 50 & 14.9 & 9 & 2.9 \\
\hline
\end{tabular}

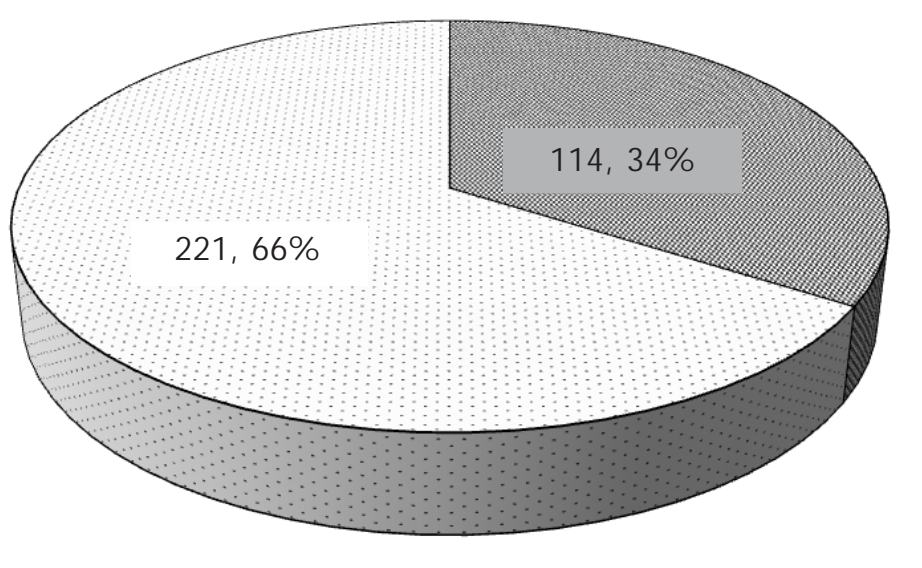

Global PSQI Score $<5 \quad$ QGlobal PSQI Score $\geq 5$ (poor sleep quality)

Figure 1. Prevalence of poor sleep quality based on PSQI scores. 
Table 2. Univariate analysis of sociodemographic variables and Global PSQI Scores' classification among college students in Rishikesh

\begin{tabular}{|c|c|c|c|c|c|c|c|}
\hline \multirow[t]{3}{*}{ Characteristics } & & \multicolumn{6}{|c|}{ Global PSQI Scores } \\
\hline & & \multicolumn{2}{|c|}{$\begin{array}{c}\geq 5 \text { (Poor sleep } \\
\text { quality) }\end{array}$} & \multicolumn{2}{|c|}{$<5$} & \multirow[t]{2}{*}{$P$ value } & \multirow[t]{2}{*}{$\begin{array}{l}\text { Unadjusted OR } \\
(95 \% \text { CI })\end{array}$} \\
\hline & & No. & $\%$ & No. & $\%$ & & \\
\hline \multirow[t]{2}{*}{ Gender } & Male & 78 & 65.55 & 41 & 34.45 & 0.90 & $0.97(0.60-1.56)$ \\
\hline & Female & 143 & 66.2 & 73 & 33.8 & & \\
\hline \multirow[t]{2}{*}{ Course pursuing } & MBBS/ Nursing & 91 & 64.5 & 50 & 35.4 & 0.63 & $0.89(0.56-1.41)$ \\
\hline & Allied (Paramedical) & 130 & 67.0 & 64 & 33.0 & & \\
\hline \multirow[t]{2}{*}{ Year of the course } & $1^{\text {st }}$ year & 76 & 64.4 & 42 & 35.6 & 0.65 & $0.89(0.56-1.44)$ \\
\hline & $2^{\text {nd }}$ year onwards & 145 & 66.8 & 72 & 33.2 & & \\
\hline \multirow[t]{2}{*}{ Religion } & Hindu & 213 & 66.2 & 109 & 33.8 & 0.73 & $1.22(0.39-3.86)$ \\
\hline & Others & 8 & 61.5 & 5 & 38.5 & & \\
\hline \multirow[t]{2}{*}{ Residence } & Hostel & 139 & 66.5 & 70 & 33.5 & 0.79 & $1.06(0.67-1.69)$ \\
\hline & Home & 82 & 65.1 & 44 & 34.9 & & \\
\hline \multirow{2}{*}{$\begin{array}{l}\text { Type of family for } \\
\text { those who stay at home }\end{array}$} & Nuclear & 48 & 62.3 & 29 & 37.7 & 0.42 & $0.73(0.34-1.57)$ \\
\hline & Extended/ Joint & 34 & 69.4 & 15 & 30.6 & & \\
\hline \multirow{3}{*}{$\begin{array}{l}\text { Total members in the } \\
\text { family }\end{array}$} & $\leq 4$ & 26 & 72.2 & 10 & 27.8 & $0.20 *$ & 1.00 \\
\hline & $5-7$ & 49 & 63.6 & 28 & 36.4 & & 0.67 \\
\hline & $>7$ & 7 & 53.8 & 6 & 46.2 & & 0.45 \\
\hline \multirow{3}{*}{$\begin{array}{l}\text { Total no. of rooms } \\
\text { in the house }\end{array}$} & $\leq 2$ & 13 & 76.5 & 4 & 23.5 & $0.68 *$ & 1.00 \\
\hline & $3-5$ & 58 & 71.6 & 23 & 28.4 & & 0.77 \\
\hline & $>6$ & 7 & 70 & 3 & 30 & & 0.71 \\
\hline \multirow{2}{*}{$\begin{array}{l}\text { Overcrowding } \\
\text { (Number of rooms } \\
\text { per person criteria) }\end{array}$} & Present & 22 & 66.7 & 11 & 33.3 & 0.82 & $1.10(0.47-2.54)$ \\
\hline & Absent & 60 & 64.5 & 33 & 35.5 & & \\
\hline \multirow{2}{*}{$\begin{array}{l}\text { Presence of TV in } \\
\text { bedroom }\end{array}$} & Yes & 43 & 64.2 & 24 & 35.8 & 0.82 & $0.92(0.44-1.91)$ \\
\hline & No & 39 & 66.1 & 20 & 33.9 & & \\
\hline $\begin{array}{l}\text { Family history of } \\
\text { diagnosed sleep }\end{array}$ & Yes/ May be & 14 & 73.7 & 5 & 26.3 & 0.46 & $1.47(0.51-4.20)$ \\
\hline disorders & No & 207 & 65.5 & 109 & 34.5 & & \\
\hline \multirow{2}{*}{$\begin{array}{l}\text { Presence of any } \\
\text { chronic illness }\end{array}$} & Yes & 9 & 75 & 3 & 25 & 0.5 & $1.57(0.41-5.92)$ \\
\hline & No & 212 & 65.6 & 111 & 34.4 & & \\
\hline
\end{tabular}

Row percentages are calculated. *p values based on chi-square for trend; chi-square used otherwise. p value of $<0.05$ is considered significant. 
Table 3. Univariate analysis of academic and behavioural variables and Global PSQI scores' classification among college students in Rishikesh

\begin{tabular}{|c|c|c|c|c|c|c|c|}
\hline \multirow[t]{3}{*}{ Characteristics } & & \multicolumn{6}{|c|}{ Global PSQI Scores } \\
\hline & & \multicolumn{2}{|c|}{$\begin{array}{c}\geq 5 \text { (Poor sleep } \\
\text { quality) }\end{array}$} & \multicolumn{2}{|c|}{$<5$} & \multirow[t]{2}{*}{$P$ value } & \multirow[t]{2}{*}{$\begin{array}{l}\text { Unadjusted OR } \\
\quad(95 \% \text { CI })\end{array}$} \\
\hline & & No. & $\%$ & No. & $\%$ & & \\
\hline \multirow{2}{*}{$\begin{array}{l}\text { Satisfied with } \\
\text { your studies }\end{array}$} & Yes & 149 & 63.1 & 87 & 36.9 & 0.09 & $0.64(0.38-1.07)$ \\
\hline & No & 72 & 72.7 & 27 & 28.3 & & \\
\hline \multirow{2}{*}{$\begin{array}{l}\text { Parents satisfied } \\
\text { with your result }\end{array}$} & Yes & 179 & 64.2 & 100 & 35.8 & 0.11 & $0.59(0.31-1.14)$ \\
\hline & No & 42 & 75.0 & 14 & 25.0 & & \\
\hline \multirow{5}{*}{$\begin{array}{l}\text { Percentage marks obtained } \\
\text { in last two exams }\end{array}$} & $\leq 50=1$ & 3 & 60 & 2 & 40 & $0.79 *$ & - \\
\hline & $51-60=2$ & 52 & 69.3 & 23 & 30.6 & & \\
\hline & $61-75=3$ & 121 & 63.4 & 70 & 36.6 & & \\
\hline & $>75=4$ & 37 & 72.5 & 14 & 27.5 & & \\
\hline & Don't know=5 & 6 & 85.7 & 1 & 14.3 & & \\
\hline \multirow[t]{2}{*}{ Practice yoga/ meditation } & Yes & 38 & 55.9 & 30 & 44.1 & 0.049 & $0.58(0.33-1.00)$ \\
\hline & No & 183 & 68.5 & 84 & 31.5 & & \\
\hline \multirow{3}{*}{$\begin{array}{l}\text { Frequency of yoga/ } \\
\text { meditation }\end{array}$} & Daily & 16 & 69.6 & 7 & 30.4 & $0.39 *$ & - \\
\hline & 2-3 times a week & 13 & 41.9 & 18 & 58.1 & & \\
\hline & Weekly & 8 & 61.5 & 5 & 38.5 & & \\
\hline \multirow[t]{2}{*}{ Alcohol use } & Never users & 197 & 66.8 & 98 & 33.2 & 0.39 & $1.34(0.68-2.63)$ \\
\hline & Ever users & 24 & 60 & 16 & 40 & & \\
\hline \multirow[t]{2}{*}{ Stress (PSS-10) } & Low stress & 10 & 37.1 & 17 & 62.9 & 0.00 & $0.28(0.12-0.64)$ \\
\hline & Moderate/ High stress & 202 & 68.5 & 97 & 31.5 & & \\
\hline \multirow{3}{*}{$\begin{array}{l}\text { Type of activity } \\
\text { for recreation }\end{array}$} & Vigorous intensity activity & 28 & 25.5 & 35 & 16.7 & 0.21 & - \\
\hline & Moderate intensity activity & 37 & 33.6 & 80 & 38.3 & & \\
\hline & Sedentary activity & 83 & 75.5 & 164 & 78.5 & & \\
\hline \multirow{2}{*}{$\begin{array}{l}\text { Mobile use before } \\
\text { going to bed }\end{array}$} & Yes & 195 & 68.4 & 90 & 31.6 & 0.02 & $2.00(1.08-3.67)$ \\
\hline & No & 26 & 52.0 & 24 & 48.0 & & \\
\hline \multirow[t]{2}{*}{ Screen time } & $\leq 2 \mathrm{hrs}$ & 45 & 56.3 & 35 & 43.8 & 0.035 & $1.73(1.03-2.90)$ \\
\hline & $>2$ hrs & 176 & 69.0 & 79 & 31.0 & & \\
\hline \multicolumn{2}{|l|}{$\begin{array}{l}\text { Duration of screen } \\
\text { time in weekdays } \\
\text { (Mean, SD) }\end{array}$} & \multicolumn{2}{|c|}{$292.18,196.50$} & \multicolumn{2}{|c|}{$264.34,177.72$} & 0.10 & - \\
\hline \multicolumn{2}{|l|}{$\begin{array}{l}\text { Duration of screen } \\
\text { time at weekends } \\
\text { (Mean, SD) }\end{array}$} & \multicolumn{2}{|c|}{$325.85,201.50$} & \multicolumn{2}{|c|}{$325.07,210.48$} & 0.76 & - \\
\hline
\end{tabular}

Row percentages are calculated.

*p values based on chi-square for trend; chi-square used otherwise. p value of $<0.05$ is considered significant 
Univariate analysis of academic and behavioural variables as predictors showed that students practicing yoga/ meditation were less likely to have PSQ (55.9\%) than those who did not (68.5\%), (OR (95\% CI) 0.58 (0.33-1.00)). Those with mild stress (37.1\%) were less likely to have PSQ as compared to those with moderate to severe level of stress (68.5\%), (OR (95\% CI) 0.28
(0.12-0.64)). Students having a screen time of $>2$ hours/ day were more likely to have PSQ (OR (95\% CI) 1.73 (1.03-2.90)). Also, those using mobile before going to bed were more likely (68.4\%) to have PSQ, (OR (95\% CI) 2.00 (1.08-3.67)). Satisfaction with studies or alcohol use did not have any significant association with sleep quality (Table 3).

Table 4. Binary logistic regression to determine predictors of poor sleep quality among college going students

\begin{tabular}{|c|c|c|c|c|c|c|}
\hline \multirow[t]{2}{*}{ Variables } & \multirow[t]{2}{*}{ Reference Category } & \multirow[t]{2}{*}{$B$} & \multirow[t]{2}{*}{ Sig. } & \multirow[t]{2}{*}{$\operatorname{Exp}(B) / O R$} & \multicolumn{2}{|c|}{ 95\% CI for $\operatorname{Exp}(B)$} \\
\hline & & & & & Lower & Upper \\
\hline Age & - & -0.131 & 0.116 & 0.877 & 0.745 & 1.033 \\
\hline Gender & Female & -0.007 & 0.979 & 0.993 & 0.593 & 1.662 \\
\hline Course & Medical & 0.357 & 0.342 & 1.429 & 0.685 & 2.982 \\
\hline Year & 1 st year & 0.242 & 0.428 & 1.274 & 0.700 & 2.316 \\
\hline Residence & Home & 0.181 & 0.609 & 1.198 & 0.599 & 2.398 \\
\hline Yoga & No & -0.763 & 0.012 & 0.466 & 0.257 & 0.845 \\
\hline Self-satisfaction with studies & No & -0.414 & 0.201 & 0.661 & 0.350 & 1.247 \\
\hline Parent's satisfaction & No & -0.469 & 0.217 & 0.625 & 0.297 & 1.318 \\
\hline Marks >70\% & Marks $\leq 70 \%$ & 0.219 & 0.423 & 1.245 & 0.728 & 2.128 \\
\hline Marks (DK) & Marks $\leq 70 \%$ & 0.955 & 0.402 & 2.600 & 0.278 & 24.277 \\
\hline Stress & Mild & 1.412 & 0.002 & 4.102 & 1.711 & 9.833 \\
\hline Mobile use & No & 0.671 & 0.044 & 1.956 & 1.020 & 3.753 \\
\hline Constant & & 1.756 & 0.315 & 5.789 & & \\
\hline
\end{tabular}

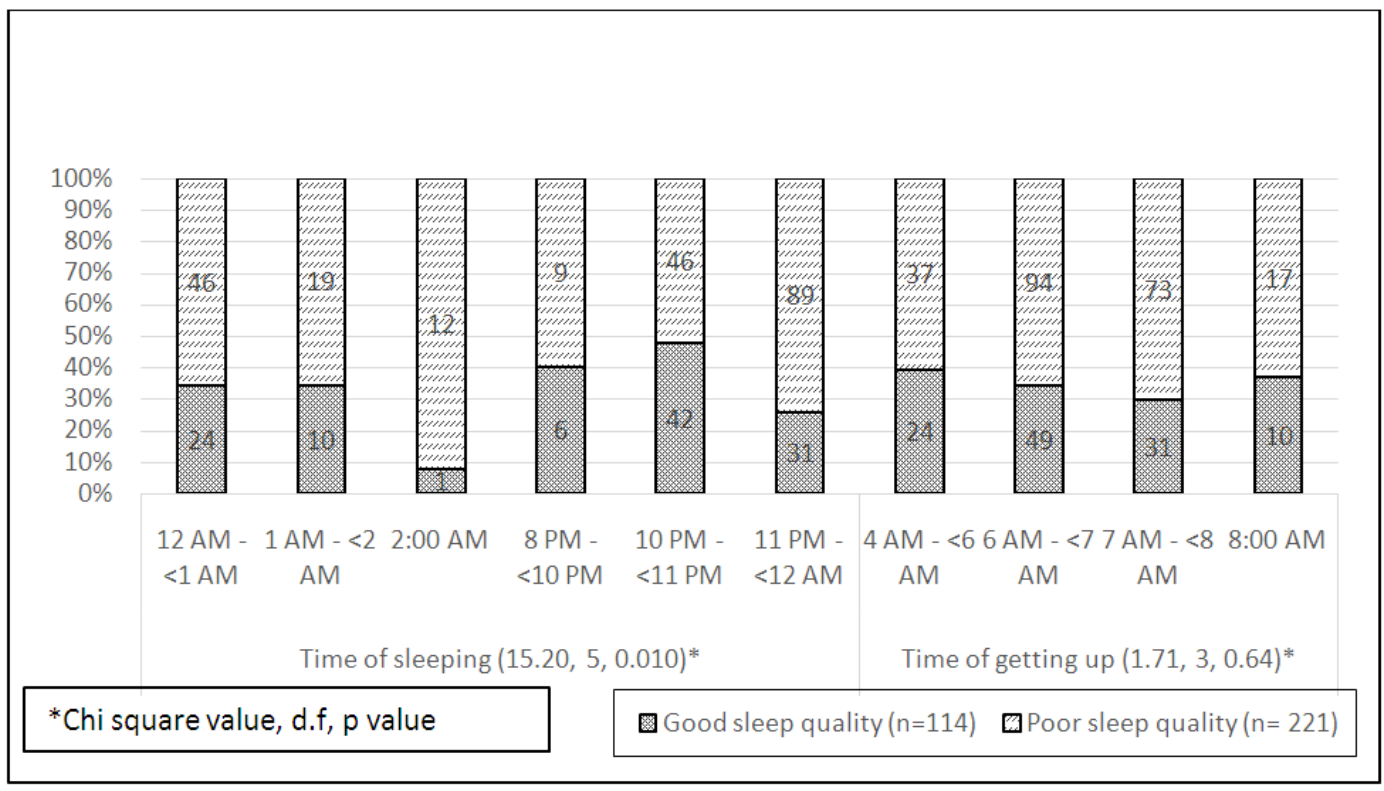

Figure 2. Association of sleep quality with time of sleeping and time of getting up. 
Time of sleeping was observed to be significantly associated with sleep quality ( $\mathrm{p}$ value $<0.05$ ) in the present study. Using Bonferroni Chi-square residual analysis, to assess whether the percentages in each cell are significantly different from expected cell percentages, we obtained adjusted standardized residuals for each of the cells. The results showed that observed percentages of good and PSQ, among those sleeping between 10-11 pm were significantly different from expected values according to null hypothesis (p value $<0.004$ ). The time of getting up however did not show any association with sleep quality (p value $>0.05$ ) (Figure 2 ).

The model for logistic regression analysis to predict the probability of respondent's PSQ included sociodemographic variables (age, gender, course, year of study, residence), personal characteristics (yoga, stress and mobile use before bed) and academic related characteristics (Self-satisfaction, parents' satisfaction with studies and marks obtained in last exam) as predictor variables. A test of the full model versus a model with intercept only was statistically significant, $\chi^{2}(12, \mathrm{~N}=335)=29.63$, $\mathrm{p}<.005$. Hosmer and Lemeshow test results also supported the model against null model $\left(\chi^{2}(8, \mathrm{~N}=335)=6.84, \mathrm{p}>0.05\right)$. The model could explain $11.7 \%$ of the variability in sleep quality (Nagelkerke R Square value of 0.117 ), which was the best among all the models tested. Results showed that yoga, stress and use of mobile before bedtime had significant effects on sleep quality. The odds ratio for yoga indicates that a student is 0.47 times less likely to have PSQ if s/he practices yoga than those who do not. The effect of stress was highest among all the significant predictors and it was observed that those with moderate or severe stress had 4.1 times higher odds of having PSQ than those with mild stress. Although significant, the effect of mobile use before bedtime was smaller than that of stress, with the odds of PSQ being 1.96 times among users versus non-users of mobile.

Other factors such as pursuing other courses of study (OR 1.43), studying in second year onwards (1.27), staying in hostels (OR 1.20) and obtaining $>70 \%$ marks in last exam (OR 1.24) also had OR of greater than one but did not achieve statistical significance.

\section{Discussion}

This is the first study of its kind conducted in the state of Uttarakhand and addresses an important issue of quality of sleep among college going students pursuing different courses, thus providing us a more generalized information about the sleep pattern and its correlates among college students. We used PSQI questionnaire in this study, which has been demonstrated to have good internal consistency, internal homogeneity and diagnostic characteristics as compared to Polysomnography among young adults [20]. It has also been used in several other community-based studies in Indian context [21,22].

The findings of the study are very relevant and highlight the importance of having good sleep which is characterized by at least 8 hours of sleep, $<30$ minutes of sleep latency, minimal sleep disturbances, no or minimal use of sleep medication and no daytime disturbances due to inadequate sleep [23]. The results of this study are not very encouraging as we expected a lower prevalence of PSQ among students, considering the fact that Rishikesh, being the Yoga capital of world has a spiritual undertone in its way of life. However, as is evident from the study, students seem uninfluenced by the calm, serene and slowpaced environment of this place and had higher prevalence of PSQ (66\%) than that reported by several other studies conducted in India and abroad. Community-based Indian studies reported a prevalence of $62.6 \%$ and $33.7 \%$, while those among medical students reported $47.9 \%$ and $49 \%$ respectively [21, 22, 24, 25]. Studies done among college students in other countries have also reported a lower prevalence (60\%, 48,1\% and 38.9\%) [26-28].

Self-reported sleep inefficiency in Asian population, defined as a PSQI score $>5$, has been reported to be $27.2 \%$, which is quite low as compared to the present study and highlights the importance of conducting such studies in vulnerable population groups such as college students [29]. Another study in China reported a prevalence of $13.97 \%$ taking PSQI score of $\geq 8$ as cut off, which compared with $21.2 \%$ in present study [30].

The mean Global PSQI scores in the present study $(5.78 \pm 2.55)$ were also reported to be higher than most of the other studies such as that by Kaur G et al (4.77 \pm 2.518), Giri PA(5.28 (2.39)) and Xianchen L et al (5.26 \pm 2 . 38 ), with an exception of Shad R et al (6.45 \pm 2.85 ) [21, 22, 25, 30].

A systematic review, conducted to assess the problem of global sleep loss epidemic, reported that that the markers of sleep quality have definitely declined. However, data from India was not included in this study due to lack of availability. The present study would provide data from Indian context for comparisons in future systematic reviews and brings forth important points [31].

Problems in sleep quality, such as sleep duration of $<6$ hours reported in more than half of respondents, corroborates with the world-wide statistics of sleep deprivation [7]. Reduced sleep duration affects optimal functioning and is a major point of concern. It has been linked to risk and severity of Type 2 diabetes also [32]. Late sleeping hours, with just $4.5 \%$ students going to bed between $8 \mathrm{pm}$ and $10 \mathrm{pm}$, is expected to disrupt circadian rhythm in due course of time and lead to associated problems [33].

Habitual sleep efficiency which is expressed as the ratio of total hours of sleep and total hours in bed expressed as percentage, was reported to be more than $75 \%$ in most of the students (85.7\%) and was the second most encouraging finding with respect to various components of PSQI, after non-use of sleep medications (93.1\%). 
Daytime dysfunction reported in 61.7\% respondents, was quite high necessitating corrective measures, as it may compromise their academic performance and may lead to increased risk of accidents [28].

Yoga and meditation, which have been recognized as effective relaxation techniques since ages, were found to have a positive association with better sleep quality. This aspect has not been studied in other studies conducted among college students and is unique to our study. Low stress was also found to have protective effect, as has been demonstrated by several other studies [34,35].

We made a unique observation in terms of mobile use. Mobile users just before bedtime had a two-times higher odds of PSQ as compared to non-users, whereas mean hours of screen time was not associated with sleep quality, thereby stressing the importance of refraining from use of devices just before bedtime for a good quality sleep. The use of mobile just before bedtime shifts the sleeping time, which is an important component of sleep quality. Association between hours of mobile use, using 2 hours as the cut off, and sleep disorders has been highlighted in several other studies, and we observed a similar finding in univariate analysis [36,37]. Mean hours of screen time was quite high in the present study and is worrisome.

\section{Limitations}

Being a cross sectional study, the association of predictor variables with sleep quality need confirmation through comparative studies. The ability to recruit only those individuals present on the day of administration of questionnaire was an inherent limitation and may limit generalizability of the study.

\section{Conclusion and Recommendations}

Prevalence of PSQ was quite high, and irrespective of various independent variables under study, the quality of sleep was poor in most students, emphasizing the need of universalizing the interventions. It is recommended that students maintain healthy sleeping habits by adopting methods for tackling stress in day-to-day life. Yoga/ meditation may prove to be quite helpful in relaxing the mind and needs to be popularized in colleges. In addition, refraining from over use of electronic devices is recommended for a timely and proper sleep at night and maintenance of circadian rhythm. It is also important that use of electronic devices before going to bed may be restricted for better sleep quality. Although no significant association was observed between alcohol use and sleep quality, it is still recommended that alcohol use at this age be stopped to prevent addiction in later life.

\section{Acknowledgments}

Above research was supported with the aid of Indian Council of Medical Research, New Delhi, India. The funders had no function in study layout, data collection and analysis, selection to post, or coaching of the manuscript. The authors would like to acknowledge the support of administrative authorities of all the colleges for their full cooperation.

\section{References}

1. Marieb, Elaine Nicpon. Essentials of Human Anatomy and Physiology. 3rd ed. London: Benjamin/Cumming;1995.

2. Jensen DP, Herr KA. Sleeplessness. The Nursing clinics of North America. 1993; 28(2): 385-405.

3. Wehr TA, Moul DE, Barbato G, Giesen HA, Seidel JA, Barker $\mathrm{CH}$, Bender $\mathrm{CH}$. Conservation of photoperiodresponsive mechanisms in humans. American Journal of Physiology-Regulatory, Integrative and Comparative Physiology 1993; 265(4): R846-57.

4. Van Dongen H, Maislin G, Mullington JM, Dinges DF. The cumulative cost of additional wakefulness: doseresponse effects on neurobehavioral functions and sleep physiology from chronic sleep restriction and total sleep deprivation. Sleep 2003; 26(2): 117-26.

5. Rodéhn M. The importance of sleep. Nursing Standard (Royal College of Nursing (Great Britain): 1987). 1999; 13(24): 44-7.

6. Oswald I. Sleep. London: Penguin Books; 1980.

7. This Data Shows A Shocking Worldwide Lack of Sleep. Available from https://www.dreams.co.uk/sleep-mattersclub/data-shows-a-shocking-worldwide-lack-of-sleep/ Accessed on April 10, 2020.

8. Kang JH, Chen SC. Effects of an irregular bedtime schedule on sleep quality, daytime sleepiness, and fatigue among university students in Taiwan. BMC Public Health 2009; 9(1): 248.

9. Keshavarz AA, Ghalehbandi M. Sleep quality and its correlation with general health in pre-university students of Karaj, Iran 2009: 44-49.

10. Reite M. Concise Guide to Evaluation and Management of Sleep Disorders. Washington, DC: American Psychiatric Press; 1989.

11. Dement WC, Mitler MM. It's time to wake up to the importance of sleep disorders. Jama 1993; 269(12): 154850 .

12. Jensen DR. Understanding sleep disorders in a college student population. Journal of College Counseling 2003; 6(1): 25-34.

13. Ahrberg K, Dresler M, Niedermaier S, Steiger A, Genzel L. The interaction between sleep quality and academic performance. Journal of Psychiatric Research 2012; 46(12): 1618-22.

14. Panda S, Taly AB, Sinha S, Gururaj G, Girish N, Nagaraja D. Sleep-related disorders among a healthy population in South India. Neurology India 2012; 60(1): 68.

15. Lawanga SK, Lemeshaw S. Sample size determination in health studies: A practical manual. Geneva. WHO; 1991. 
16. Sleep Quality Assessment (PSQI). Available at https:// aurora.edu/documents/wellness/assessment.pdf. Accessed on April 102020.

17. AUDIT C-Overview. https://www.integration.samhsa.gov/ images/res/tool_auditc.pdf. Accessed on April 10, 2020.

18. Cohen S, Kamarck T, Mermelstein R. A global measure of perceived stress. Journal of Health and Social Behavior 1983: 385-96.

19. World Health Organization: Global Physical Activity Questionnaire (GPAQ) analysis guide. http://www.who.int/ chp/steps/resources/ GPAQ_Analysis_Guide.pdf. Accessed on May 15, 2019.

20. Buysse DJ, Reynolds CF, 3rd, Monk TH, Berman SR, Kupfer DJ. The Pittsburgh sleep quality index: a new instrument for psychiatric practice and research. Psychiatry Res. 1988; 28: 193-213.

21. Shad R, Thawani R, Goel A. Burnout and sleep quality: a cross-sectional questionnaire-based study of medical and non-medical students in India. Cureus 2015; 7(10).

22. Kaur G, Sharma V, Singh A. Association of sleep quality with general health: an Indian college students' study. Int $J$ Med Sci Public Health 2015; 4(12): 1767.

23. What is Good Quality Sleep? National Sleep Foundation. https://www.sleepfoundation.org/press-release/what-goodquality-sleep. Accessed on April 10, 2020.

24. Chutani A, Shenvi DN, Singhal A. Sleep, Sleepiness and Medical College Students: A Comparative Study among Medical and Paramedical Students of a Tertiary Care Teaching Hospital from a West Indian Metropolitan City. Annals of Medical and Health Sciences Research 2017; 7(2): 85-91.

25. Giri PA, Baviskar MP, Phalke DB. Study of sleep habits and sleep problems among medical students of Pravara Institute of Medical Sciences Loni, Western Maharashtra, India. Annals of Medical and Health Sciences Research 2013; 3(1): 51-4.

26. Lund HG, Reider BD, Whiting AB, Prichard JR. Sleep patterns and predictors of disturbed sleep in a large population of college students. Journal of Adolescent Health 2010; 46(2): 124-32.

27. Lohsoonthorn V, Khidir H, Casillas G, Lertmaharit S, Tadesse MG, Pensuksan WC, Rattananupong T, Gelaye
B, Williams MA. Sleep quality and sleep patterns in relation to consumption of energy drinks, caffeinated beverages, and other stimulants among Thai college students. Sleep and Breathing 2013; 17(3): 1017-28.

28. Medeiros AL, Mendes DB, Lima PF, Araujo JF. The relationships between sleep-wake cycle and academic performance in medical students. Biological Rhythm Research 2001; 32(2): 263-70.

29. Tan A, Cisulli PA, Hong Y, Tan LW, Van Dam RM, Bin YS. Self-reported sleep characteristics in a multi-ethnic asian population: the Singapore health studies. Sleep Medicine 2017; 40: e35.

30. Xianchen L. Sleep quality and its correlates in college students. Chinese Mental Health Journal 1995; 4: 04.

31. Hoyos C, Glozier N, Marshall NS. Recent evidence on worldwide trends on sleep duration. Current Sleep Medicine Reports 201; 1(4): 195-204.

32. Knutson KL, Ryden AM, Mander BA, Van Cauter E. Role of sleep duration and quality in the risk and severity of type 2 diabetes mellitus. Archives of Internal Medicine 2006; 166(16): 1768-74.

33. Hower IM, Harper SA, Buford TW. Circadian rhythms, exercise, and cardiovascular health. Journal of Circadian Rhythms 2018; 16.

34. Sawah MA, Ruffin N, Rimawi M, Concerto C, Aguglia E, Chusid E, Infortuna C, Battaglia F. Perceived stress and coffee and energy drink consumption predict poor sleep quality in podiatric medical students: a cross-sectional study. Journal of the American Podiatric Medical Association 2015; 105(5): 429-34.

35. Lemma S, Gelaye B, Berhane Y, Worku A, Williams MA. Sleep quality and its psychological correlates among university students in Ethiopia: a cross-sectional study. BMC Psychiatry 2012; 12(1): 237.

36. Soni R, Upadhyay R, Jain M. Prevalence of smart phone addiction, sleep quality and associated behaviour problems in adolescents. International Journal of Research in Medical Sciences 2017; 5(2): 515-9.

37. Demirci K, Akgönül M, Akpinar A. Relationship of smartphone use severity with sleep quality, depression, and anxiety in university students. Journal of Behavioral Addictions. 2015; 4(2): 85-92. 